\title{
Why is high persistence alone a major cause of concern?
}

\section{Review Article}

Author(s):

Cousins, Ian T.; Ng, Carla A.; Wang, Zhanyun; Scheringer, Martin

Publication date:

2019-05-01

Permanent link:

https://doi.org/10.3929/ethz-b-000345064

Rights / license:

Creative Commons Attribution-NonCommercial 3.0 Unported

Originally published in:

Environmental Science: Processes \& Impacts 21(5), https://doi.org/10.1039/c8em00515j 


\section{Environmental Science Processes \& Impacts}

Check for updates

Cite this: Environ. Sci.: Processes Impacts, 2019, 21, 781

Received 5th November 2018 Accepted 28th March 2019

DOI: 10.1039/c8em00515j

rsc.li/espi

\section{Why is high persistence alone a major cause of concern?}

\author{
Ian T. Cousins, (D) a Carla A. Ng, (D) ${ }^{b}$ Zhanyun Wang (D) ${ }^{c}$ and Martin Scheringer (DD *d
}

Persistence is a hazard criterion for chemicals enshrined in chemical regulation worldwide. In this paper, we argue that the higher the persistence of a chemical, the greater the emphasis that it should be given in chemicals assessment and decision making. We provide case studies for three classes of highly persistent chemicals (chlorofluorocarbons, polychlorinated biphenyls, and per- and polyfluoroalkyl substances) to exemplify problems unique to highly persistent chemicals, despite their otherwise diverse properties. Many well-known historical chemical pollution problems were the result of the release of highly persistent chemicals. Using evaluative modeling calculations, we demonstrate that if a chemical is highly persistent, its continuous release will lead to continuously increasing contamination irrespective of the chemical's physical-chemical properties. We argue that these increasing concentrations will result in increasing probabilities of the occurrence of known and unknown effects and that, once adverse effects are identified, it will take decades, centuries or even longer to reverse contamination and therefore effects. Based on our findings we propose that high persistence alone should be established as a sufficient basis for regulation of a chemical, which we term the "P-sufficient approach". We argue that regulation on high persistence alone is not over-precautionary given the historical and ongoing problems that persistent chemicals have caused. Regulation of highly persistent chemicals, for example by restriction of emissions, would not only be precautionary, but would serve to prevent poorly reversible future impacts.

\section{Environmental significance}

Chemicals that are resistant to degradation in the environment are called persistent. High persistence (degradation half-lives of six months or more) has important implications for the behavior of chemicals in the environment. Persistent chemicals are distributed widely, often globally, and reach (much) higher concentrations than short-lived chemicals emitted at the same rate. We illustrate these features of highly persistent chemicals using a unit-world environmental fate model. Over the last decades, highly persistent chemicals such as polychlorinated biphenyls have caused serious impacts on the environment and human health. We argue that high persistence should be given particular emphasis in chemicals assessment and management and that highly persistent chemicals should be regulated on the basis of their persistence alone (P-sufficient approach).

\section{Introduction}

The persistence of organic chemicals has been an important element of chemical hazard assessment for over 40 years. ${ }^{\mathbf{1 - 4}}$ High persistence indicates the potential for long-lasting environmental and human exposure to a chemical that is difficult to control and reverse..$^{5-7}$ The importance of persistence is reflected by the persistence (P) criterion in the PBT (persistence,

\footnotetext{
${ }^{a}$ Department of Environmental Science and Analytical Chemistry (ACES), Stockholm University, SE-10691 Stockholm, Sweden

${ }^{b}$ Department of Civil \& Environmental Engineering, University of Pittsburgh, 3700 O'Hara St, Pittsburgh, PA 15261, USA

${ }^{c}$ Chair of Ecological Systems Design, Institute of Environmental Engineering, ETH Zürich, 8093 Zürich, Switzerland

${ }^{d}$ Institute of Biogeochemistry and Pollutant Dynamics, ETH Zürich, Universitätstr. 16, 8092 Zürich, Switzerland. E-mail: scheringer@usys.ethz.ch
}

bioaccumulation potential, toxicity) assessment schemes used under the Stockholm Convention on Persistent Organic Pollutants and in an increasing number of jurisdictions such as Australia, Canada, the EU, Japan, South Korea and the US, and by the "very persistent" (vP) criterion under the EU chemicals regulation, REACH. A review of the historical development of international persistence criteria is provided by Matthies and Beulke (2017). ${ }^{8}$ Here we suggest that the higher the persistence of a chemical, the greater the emphasis that it should be given in chemicals assessment and decision-making. Specifically, the aim of this work is to provide a transparent and conclusive reasoning why, from a certain point on, the persistence of a chemical indicates such a high level of concern that it should be given strong priority in the assessment and management of such a chemical.

The focus of this work is on the persistence of organic chemicals, ${ }^{9}$ which is generally quantified in terms of 
degradation half-lives in individual environmental media ("single-media half-lives"). ${ }^{8,10}$ Not covered are synthetic polymers; stable ("persistent") inorganic substances such as water, nitrogen $\left(\mathrm{N}_{2}\right)$, salts, mineral substances (e.g. concrete and sand), and metals such as anthropogenically mobilized mercury, cadmium and lead. Although synthetic polymers are not explicitly included, some challenges associated with synthetic polymers, which are poorly degradable by their very nature, are addressed in the Discussion section.

By "high persistence" we mean that a chemical has at least one degradation half-life exceeding, for example, 6 months. Importantly, this value is just indicative and not meant as a proposal for a regulatory cutoff value (regulatory implementation of the approach proposed here will be a separate step).

The particular importance of the persistence of chemicals was already pointed out by Stephenson $(1977)^{1}$ more than 40 years ago:

"On the face of it there appears little reason to be concerned about a material which, even though present in the environment, it not causing any detectable damage. On the other hand, persistent materials, because of this property, will accumulate in the environment for as long as they are released. Since the environment is not effective at cleansing itself of these materials, they will remain for indefinite periods which were not recognized at the time of their original release. The problem could become entirely out of control and it would be extremely difficult if not impossible to do anything about it. Materials which are strongly persistent can accumulate to rather high levels in the environment and effects which would not otherwise be important could become so".

Since then, this point has been reiterated by several authors every 5-10 years. ${ }^{2,3,5,7,10-14}$ Our final conclusion from all of these analyses is that there may be chemicals whose persistence is so high that it is sufficient alone as a basis for the regulation of these chemicals.

Here we first present conceptual arguments that highlight the meaning of the persistence of chemicals for the occurrence of exposure and, importantly, also risks. We then use results from a multi-compartment environmental fate model to further illustrate these arguments, and finally draw conclusions for the assessment and management of highly persistent chemicals and discuss, also in the context of the precautionary principle, the "P-sufficient" approach that we introduce here.

The P-sufficient approach is intended to complement established methods of chemical risk assessment. It starts from the well-established insight that for PBT chemicals a risk assessment would be fraught with too much uncertainty and that, therefore, these chemicals should be assessed and managed on the basis of their PBT properties. ${ }^{15,16}$ Here we maintain that of these three properties $\mathrm{P}$ is of particular importance and that all chemicals that show a high persistence should be assessed and managed on the basis of their high persistence alone, irrespective of their B and T properties. This approach applies only to a small subset of organic chemicals on the market and does not have any implications for the majority of chemicals, which are not highly persistent and can be managed on the basis of existing chemical regulatory approaches.

\section{Why persistence matters and what it means}

Persistent chemicals are at the center of many of the most serious cases of environmental contamination in the last 50 years. Examples are polychlorinated biphenyls (PCBs), ${ }^{13,17}$ chlorofluorocarbons (CFCs), ${ }^{18,19}$ and per- and polyfluoroalkyl substances (PFASs). ${ }^{20}$ These cases have been investigated in much detail; Table 1 provides an overview of the chemicals' persistence, production history and the major issues that follow from their persistence. Importantly, the adverse effects caused by persistent chemicals are not limited to health effects in humans and wildlife, but also include physical and chemical effects such as ozone depletion and global warming.

The cases in Table 1 and others (e.g. PCDD/Fs, ${ }^{67-69}$ brominated flame retardants, ${ }^{70-72}$ organochlorine pesticides ${ }^{73}$ ) show that, empirically, the particular concerns caused by highly persistent chemicals have been documented in much detail. Conceptually, the essence of why high persistence is of outstanding importance in chemicals assessment is perhaps less obvious and worth clarifying here. The concern about a chemical in the environment is, of course, related to unwanted effects (of any kind, e.g. toxic effects on wildlife or humans, global warming, ozone depletion, see Table 1) that the chemical may cause. However, as has been learned from many cases in chemical risk assessment (e.g. immunotoxicity of PFASs,${ }^{57}$ endocrine disrupting effects ${ }^{74}$ effects of neonicotinoid pesticides ${ }^{75}$ ), adverse effects are difficult to predict and the scientific knowledge about effects will always remain uncertain and, importantly, incomplete. This is because the number of possible effects is infinite and it is epistemologically impossible to identify them all. This means that unexpected effects may always occur.

If unexpected effects are caused by a short-lived chemical, it is possible to rapidly cease environmental contamination by restricting or banning its use, which then also means that no additional effects will be caused by that chemical. This is why short-lived chemicals that are released to the environment at high rates should not be called "pseudo-persistent" or "semi-persistent". In such a case, high levels in the environment are observed, but they are solely caused by continuous and high emissions, not by any type of persistence of the chemical.

In contrast, in the case of highly persistent chemicals, it is not possible to cease environmental contamination within a reasonable time frame by simply restricting or banning their use. Environmental contamination by highly persistent chemicals - and the effects related to this contamination - will continue for years to decades. This poor reversibility of contamination is because highly persistent chemicals are, by definition, difficult to degrade. This implies that highly persistent chemicals will require high inputs of energy to remove 
Table 1 Overview of the persistence, production history, and major issues associated with three well-known classes of persistent chemicals. CFCs = chlorofluorocarbons; PCBs = polychlorinated biphenyls; PFASs = per- and polyfluoroalkyl substances; PFAAs = perfluoroalkyl acids; $\mathrm{PFOA}=$ perfluorooctanoic acid

\begin{tabular}{|c|c|c|c|}
\hline & CFCs & PCBs & PFASs \\
\hline Persistence & $\begin{array}{l}\text { Many decades to a century } \\
\text { or more in the } \\
\text { stratosphere }^{21}\end{array}$ & $\begin{array}{l}\text { Years to decades }{ }^{22} \text { in } \\
\text { terrestrial and aquatic } \\
\text { environments }\end{array}$ & $\begin{array}{l}\text { All PFASs are, or ultimately } \\
\text { transform into, stable } \\
\text { substances, often PFAAs. } \\
\text { PFAAs degrade slowly in the } \\
\text { air }{ }^{23} \text { and negligibly in other } \\
\text { media. }\end{array}$ \\
\hline First report(s) of presence & $\begin{array}{l}\text { Mid-1960s early } 1970 \text { s after } \\
\text { invention of the electron } \\
\text { capture detector }^{30-32}\end{array}$ & Late $1960 \mathrm{~s}^{33,34}$ & $\begin{array}{l}\text { Organofluorine fraction } \\
\text { discovered in human blood in } \\
1968{ }^{35} \text { and in } 19766^{36} \text { PFOA } \\
\text { tentatively identified using } \\
\text { NMR. }\end{array}$ \\
\hline $\begin{array}{l}\text { Start of large-scale } \\
\text { investigation }\end{array}$ & $\begin{array}{l}\text { 1970s following the } \\
\text { discovery of their depletion } \\
\text { of stratospheric ozone }{ }^{37}\end{array}$ & $\begin{array}{l}\text { 1970s following the first } \\
\text { reports of their presence }\end{array}$ & $\begin{array}{l}\text { 2000s after discovery of } \\
\text { widespread presence of PFAAs } \\
\text { in wildlife } \\
\text { blood }^{39} \text { and human }\end{array}$ \\
\hline
\end{tabular}

Major issues associated with the persistence of the chemicals Long-range transport/ previously unexpected exposure

The atmospheric lifetime of CFCs is long enough to reach, and be persistent in, the stratosphere ${ }^{32}$

Delayed identification of unexpected effects

Effectiveness of risk assessments

Effectiveness of regulatory actions
In 1973, J. Lovelock concluded "that the presence of these compounds constitutes no conceivable hazard". ${ }^{32}$ Stratospheric ozone depletion was an unknown effect at that time

International agreement was reached under the Montreal Protocol, which entered into force in 1987. The Montreal Protocol only called for a reduction in emissions of certain damaging CFCs, with later amendments agreeing to their phase-out by 2000 . Despite this phase-out, it
PCBs are globally transported $^{40}$ and present everywhere in the global environment, even in regions far away from sources (e.g. Antarctica, ${ }^{41}$ deep oceans ${ }^{42}$ and Arctic biota ${ }^{43}$ )

In the late 1960s, it was shown that PCBs bioaccumulate in Baltic food webs ${ }^{42}$ and later reproductive effects on seals ${ }^{51}$ and white-tailed eagles ${ }^{52}$ were observed. In the 1980s, it emerged that PCBs could affect unborn children ${ }^{53-55}$

Risk assessments have been continually refined (health guideline values revised downwards) from the 1920 s to the present day as new information on effects emerged $^{5}$

Regulatory action began in the late 1970s in some western countries when there was a high level of proof of effects associated with PCBs, but manufacture and use continued elsewhere. ${ }^{39}$ Despite their eventual global phase-out, PCBs are still present in many applications and will continue to be major contaminants for decades to
PFASs are globally distributed (e.g. in oceans ${ }^{44}$ and soils, ${ }^{45}$ wildlife $^{46}$ and human blood ${ }^{47}$ ) including at poles (e.g. Antarctic $^{48}$ ). Short-chain PFAAs are very mobile and can easily pass through drinking water treatment facilities ${ }^{49}$ Exposure to low doses of PFAAs at an early stage of life produces effects not captured by current regulatory testing guidelines (e.g., developmental and immuno-toxicity, endocrine disruption, etc. ${ }^{56}$ ). Consideration of immunotoxicity in health guidelines has reduced the assumed safe levels by orders of magnitude ${ }^{57}$

Risk assessments do not reflect the long-term and irreversible exposure to PFASs, ${ }^{7,20}$ many PFASs are not considered in risk assessment, and mixture toxicity and nonstandard toxicity tests are often neglected. One can therefore expect continual refinement of risk assessments $^{20}$

Regulatory action can eliminate point source emissions. However, it has no influence on what has already been emitted. Environmental redistribution of PFASs will continue for decades, and background levels will keep increasing. ${ }^{62}$ For example, PFOS levels in humans started to decrease after actions by $3 \mathrm{M}$ in 2000-2002, but there are no 
Table 1 (Contd.)

\begin{tabular}{|c|c|c|c|}
\hline & $\begin{array}{l}\text { takes decades for the ozone } \\
\text { layer to recover }\end{array}$ & $\begin{array}{l}\text { come. Levels in soils, }{ }^{59} \\
\text { sediments }^{60} \text { and biota } \\
\text { decline especially slowly }\end{array}$ & $\begin{array}{l}\text { clear trends for environmental } \\
\text { and wildlife levels yet }{ }^{63}\end{array}$ \\
\hline $\begin{array}{l}\text { Technical implications } \\
\text { for remediation }\end{array}$ & $\begin{array}{l}\text { Stopping emissions was } \\
\text { the only way to reduce } \\
\text { levels in the troposphere } \\
\text { and thus stratosphere, and } \\
\text { this was achieved through } \\
\text { international treaties }\end{array}$ & $\begin{array}{l}\text { PCBs can be found in } \\
\text { contaminated soils and } \\
\text { sediments. The most frequent } \\
\text { remediation solutions adopted } \\
\text { have been "dig and dump" and } \\
\text { "dig and incinerate", but there } \\
\text { are currently new methods } \\
\text { emerging.6 }\end{array}$ & $\begin{array}{l}\text { It is energy-intensive to break } \\
\text { the C-F bond to mineralize } \\
\text { PFASs. The most effective } \\
\text { method for large-scale } \\
\text { treatment is through } \\
\text { incineration at high } \\
\text { temperatures; new advanced } \\
\text { mineralization methods are } \\
\text { being developed. }{ }^{65} \text { Short-chain } \\
\text { PFASs are too mobile to be } \\
\text { concentrated, causing } \\
\text { additional challenges in } \\
\text { remediation }\end{array}$ \\
\hline
\end{tabular}

them from the environment, either directly for the destruction of their stable chemical bonds (e.g. incineration) or through methods to remove them from the environment that require substantial energy inputs to drive their separation from contaminated media (e.g. pump and treat: pumping water out of groundwater aquifers and subsequent treatment). Examples of the high costs associated with remediation of highly persistent chemicals are provided in Table 1. Importantly, removal or remediation is only feasible for contamination hotspots, but not for the majority of the environment such as the world's oceans.

It is logically incorrect to say that persistence merely indicates the presence of a chemical in the environment. Persistence indicates an impactful causal relationship that extends into the future: persistent chemicals that are present now will also be present to a certain extent after a considerable number of years (e.g., 25\% after 10 years if the degradation half-life is 5 years), and this fact is known already now with certainty. They have the potential to undergo long-range transport in the environment, and then an increasing number of organisms in many ecosystems as well as humans will be exposed, including ones for which this was unexpected such as the Mariana Trench in the case of PCBs. ${ }^{42}$ This includes not only chemicals that are volatile and soluble in water, but also low-volatility chemicals with very high octanol-water partition coefficients $\left(K_{\mathrm{OW}}\right)$ and octanol-air partition coefficients $\left(K_{\mathrm{OA}}\right)$, such as deca-BDE and heavy PCBs.
Furthermore, high persistence indicates that certain thresholds for causing (often unexpected) effects will be exceeded, and this can also be predicted with high reliability. If a substance is persistent, and if emissions continue at a constant rate or increase (because the substance is of technical and economic interest), the substance will attain higher and higher concentrations in the environment. In this case, the risk quotient (i.e. PEC/PNEC ratio) also increases continuously up to the point that the concentration may exceed noeffect thresholds (see examples given in Section 3, below). And even if persistent chemicals are present at low concentrations and do not (yet) exceed effect thresholds, they will still be present when, in the future, other chemicals will be emitted so that there will be co-exposure that may cause mixture effects.

In summary, the main concerns with highly persistent chemicals are:

(1) The continuous release of highly persistent chemicals will lead to widespread, long-lasting, and increasing contamination.

(2) Increasing concentrations will result in increasing probabilities that known and unknown effects occur, be it by a single chemical and/or in a mixture with other substances.

(3) Once adverse effects are identified, it will be technically challenging, energy intensive, and thus costly, to reverse the chemical contamination and therefore the effects. These measures are limited to contamination hotspots, whereas, for 
most of the environment, no remediation or clean-up will be possible.

Therefore, it is not an unsubstantiated concern about the mere presence of a chemical, but it is the much higher likelihood for particularly serious (widespread, long-lasting) adverse effects associated with highly persistent chemicals - effects that have become manifest many times as the historical examples show that confers particular importance to persistence as a hazard indicator for triggering management actions. In conclusion, concerns about a chemical are always related to effects, but for highly persistent chemicals, it should not be required that these effects are represented explicitly in the hazard assessment scheme. The hazard assessment of these chemicals should be based solely on their high persistence as a placeholder or proxy for effects.

\section{Mass-balance modeling}

Here we illustrate the implications of high persistence for the levels and time trends of chemicals in the environment using a simple multimedia environmental fate model for four example chemicals. The purpose of the modeling work is to illustrate and compare the environmental behavior of highly persistent vs. short-lived chemicals, but not to reflect any particular setting. No modeling of this type is needed in the evaluation of chemicals for persistence. The model is a so-called unit-world model $^{76}$ with three compartments: the global troposphere (height $6000 \mathrm{~m}$, volume $3.06 \times 10^{18} \mathrm{~m}^{3}$ ), the global surface ocean water (depth $100 \mathrm{~m}$, volume $3.62 \times 10^{16} \mathrm{~m}^{3}$ ), and the global surface soil (depth $0.1 \mathrm{~m}$, volume $1.48 \times 10^{13} \mathrm{~m}^{3}$ ). In each compartment, a first-order degradation process takes place; in addition, there are three non-degradative losses: diffusion to the stratosphere, settling to deep ocean water, and burial in deep soil. These non-degradative losses from the model system are not true sinks, but reflect transfer of chemical to parts of the environment not included in this particular model.

The model parameters for transfer processes between different compartments, such as the rain rate or soil runoff rate, are the same as in many other environmental fate models and are listed in Table 7.2 of the book by Mackay (2001). ${ }^{77}$

In total, we modeled four hypothetical chemicals that differ in their degradation half-lives and $K_{\text {Ow }}$ values, see Table 2 . Here we use the $K_{\mathrm{OW}}$ to describe the phase partitioning of the example chemicals. Although PFAAs, as one important class of highly persistent chemicals, are dissociated, i.e. present as anions, at environmental $\mathrm{pH}$, they partition to organic matter similar to hydrophobic organic substances with a $\log K_{\mathrm{OW}}$ of

Table 2 Chemical property data of the four example chemicals

\begin{tabular}{lrrrr}
\hline Property & Chemical A & Chemical B & Chemical C & Chemical D \\
\hline $\log K_{\mathrm{AW}}$ & -1 & -1 & -1 & -1 \\
$\log K_{\mathrm{OW}}$ & 2 & 2 & 8 & 8 \\
$t_{1 / 2}(\mathrm{~d})$ & 2 & 2000 & 2 & 2000
\end{tabular}

around two. ${ }^{78}$ For all three compartments, the same degradation half-lives of $2 \mathrm{~d}$ (chemicals A and C) and $2000 \mathrm{~d}$ (chemicals B and D) were assumed. A half-life of $2000 \mathrm{~d}$ or 5.5 years is long, but not excessively high. PFASs, for example most PFAAs, can have much longer half-lives. If PFAAs degrade, they do it so slowly that it is not observable and their half-lives could be on the order of decades, centuries or even greater. ${ }^{79}$

In a first emission scenario, we assumed the same constant emission rate to air $\left(100 \mathrm{~mol} \mathrm{~h}^{-1}\right)$ for each chemical and calculated the concentrations in air, water and soil at steadystate and in a dynamic scenario where the initial concentrations in all media are equal to zero. The absolute value of the emission rate is not relevant here because we compare results of the chemicals relative to one another. The results would be the same with any emission rate.

In reality, emissions may be constant or even increasing as long as a chemical is extensively used in open applications, often over many years or decades, and then decrease in a later stage. ${ }^{62}$ To capture this situation, we ran a second emission scenario with emissions increasing linearly for 10 years and then decreasing linearly for another 10 years. This is still an idealized scenario; for an example of a realistic emission history and the ensuing environmental distribution of a chemical, see, for example, Boucher et al. (2019). ${ }^{80}$ In this second scenario, we compare chemicals $\mathrm{C}$ and D.

The main model results are summarized in Table 3; several features of the concentration-time curves of the different chemicals are illustrated in Fig. 1 and 2. For each chemical, the results in Table 3 include the total amount present in the model system; concentrations and fractions in air, water and soil; the overall persistence; the degradation losses in comparison to non-degradation losses, and the time-to-steady-state, defined as the time at which the total amount of chemical in the system has reached $99.9 \%$ of the amount at steady-state. The overall persistence, $\tau$, is calculated as the total amount of chemical at steady-state (in mol) divided by the degradation losses (in mol $\left.\mathrm{h}^{-1}\right)$. It is related to the single-media half-lives, $t_{1 / 2, i}$, by eqn (1):

$$
\tau=\left(\sum_{i} f_{i} \frac{\ln 2}{t_{1 / 2, i}}\right)^{-1}, \quad i=\text { air, water, soil; }
$$

where the $f_{i}$ are the fractions of the chemical in the different media. If the single-media half-lives are the same (the case here), $\tau$ is equal to $t_{1 / 2} / \ln 2$.

Important observations from the scenario with constant emissions are as follows:

An increase in the degradation half-life by a factor of 1000 (from $2 \mathrm{~d}$ to $2000 \mathrm{~d}$, chemicals A vs. B, see Table 2, and chemicals C vs. D, see Fig. 1, panel (iv)) leads to an increase in the time to steady-state by a factor of 600-880 (from $20 \mathrm{~d}$ to 33-48.5 years). This increase is lower than a factor of 1000 because of the advective losses. These do not scale with the degradation halflives and, therefore, become increasingly important if the degradation half-life is longer (see Table 3, degradation losses vs. non-degradation losses). Similarly, the increase in the total inventory of chemical in the model system is only around a factor of 550 to 600 because of the increasing effect of the non- 
Table 3 Main model results for the scenario with constant emissions. Regular font: results from steady-state model. Bold: results from dynamic model

\begin{tabular}{|c|c|c|c|c|}
\hline Quantity & Chemical A & Chemical B & Chemical C & Chemical D \\
\hline Total inventory (mol) & $6.92 \times 10^{3}$ & $4.14 \times 10^{6}$ & $6.94 \times 10^{3}$ & $3.69 \times 10^{6}$ \\
\hline$c_{\mathrm{A}}\left(\mathrm{mol} \mathrm{m}^{-3}\right)$ & $2.26 \times 10^{-15}$ & $1.22 \times 10^{-12}$ & $2.25 \times 10^{-15}$ & $3.06 \times 10^{-13}$ \\
\hline$c_{\mathrm{S}}\left(\mathrm{mol} \mathrm{m}^{-3}\right)$ & $1.86 \times 10^{-14}$ & $1.43 \times 10^{-11}$ & $1.50 \times 10^{-12}$ & $1.79 \times 10^{-7}$ \\
\hline Fraction in air, $f_{\mathrm{a}}$ & 1.0 & 0.9 & 0.99 & 0.25 \\
\hline Fraction in water, $f_{\mathrm{w}}$ & 0 & 0.1 & 0.00 & 0.03 \\
\hline Sum degradation losses $\left(\mathrm{mol} \mathrm{h}^{-1}\right)$ & 99.9 & 59.8 & 99.9 & 53.2 \\
\hline $\begin{array}{l}\text { Sum non-degradation } \\
\text { losses }\left(\mathrm{mol} \mathrm{h}^{-1}\right)\end{array}$ & 0.1 & 40.2 & 0.1 & 46.8 \\
\hline Time to steady-state & $20 \mathrm{~d}$ & 33 years & $20 \mathrm{~d}$ & 48.5 years \\
\hline
\end{tabular}

degradation losses. Next, the steady-state concentrations in air, water and soil of the highly persistent chemicals, B and D (halflife $2000 \mathrm{~d}$ ), are higher by factors of 136 to $1.19 \times 10^{5}$, compared to the short-lived chemicals. Here it is the influence of the nondegradation losses in combination with different partitioning because of different $K_{\text {Ow }}$ values that explains why they differ from 1000. Chemical D, for example, is rapidly deposited from the air to soil and water with settling particles and accumulates in the soil, which is caused by its high $K_{\mathrm{OW}}$ in combination with the high half-life. Accordingly, the concentration in air of chemical D increases only by a factor of 136 compared to chemical C, but its concentration in soil increases by a factor of (i)

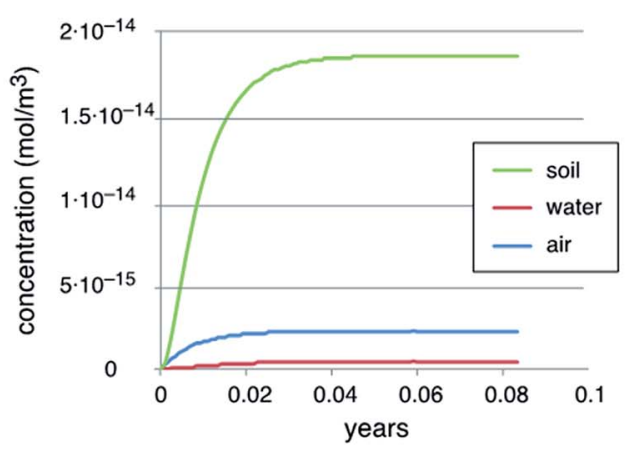

(iii)

chemical $D: t_{1 / 2}=2000$ days, $\log K_{\text {ow }}=8$

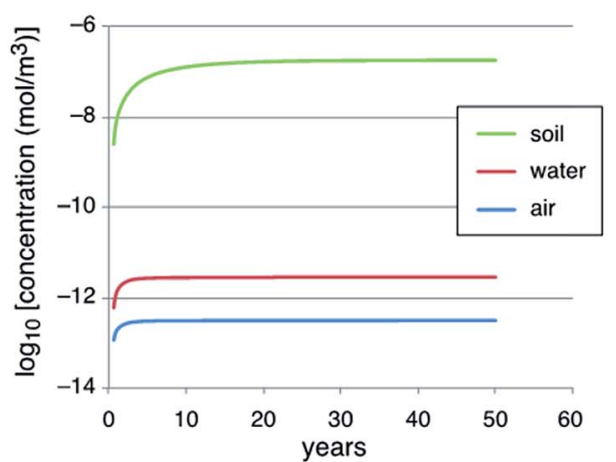

(ii)

chemical $C: t_{1 / 2}=2$ days, $\log K_{\text {ow }}=8$

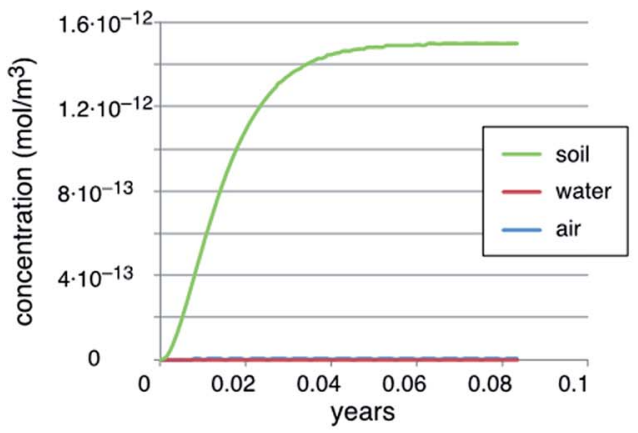

(iv)

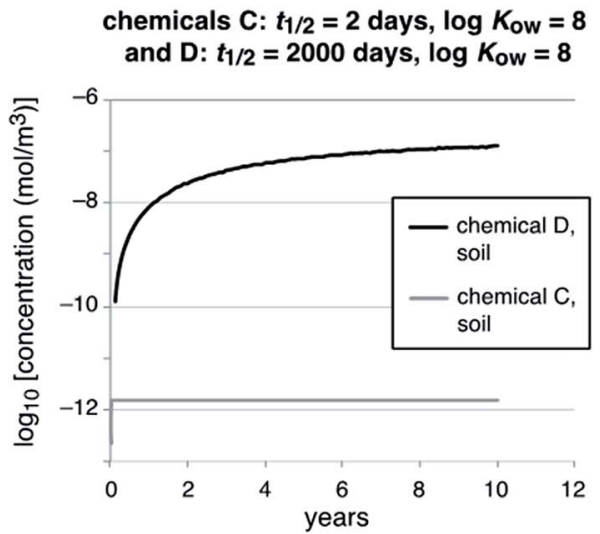

Fig. 1 Concentrations of different model chemicals as a function of time in the scenario with constant emissions (chemical B not shown). (i) Chemical $A$ with a $t_{1 / 2}=2$ days and $\log K_{\mathrm{O}}=2$ is present in all three media in appreciable amounts and reaches its steady-state after approximately 0.05 year. (ii) Chemical $C$ with $t_{1 / 2}=2$ days, but a log $K_{\text {ow }}$ of 8 , reaches its steady-state also after less than 0.1 year, but is mostly present in the soil. (iii) Chemical $D$ with $t_{1 / 2}=2000$ days and $\log K_{\mathrm{OW}}=8$ reaches its steady-state after approximately 33 years and is mostly present in the soil. (iv) Comparison of the concentrations in soil of chemicals C (short half-life) and D (long half-life). After 10 years, the concentration of chemical D is 84000 times greater than that of chemical $C$ and is still building up, see panel (iii); their emission rates are the same. 
(i) chemical C: $t_{1 / 2}=2$ days, $\log K_{\mathrm{ow}}=8$

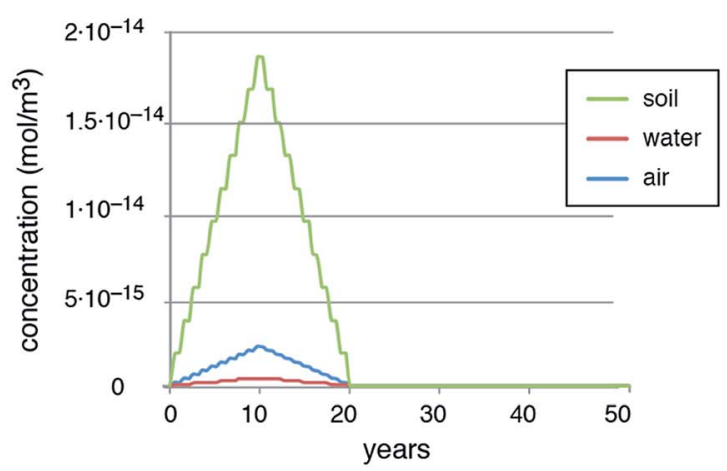

(ii) chemical D: $t_{1 / 2}=2000$ days, $\log K_{\text {ow }}=8$

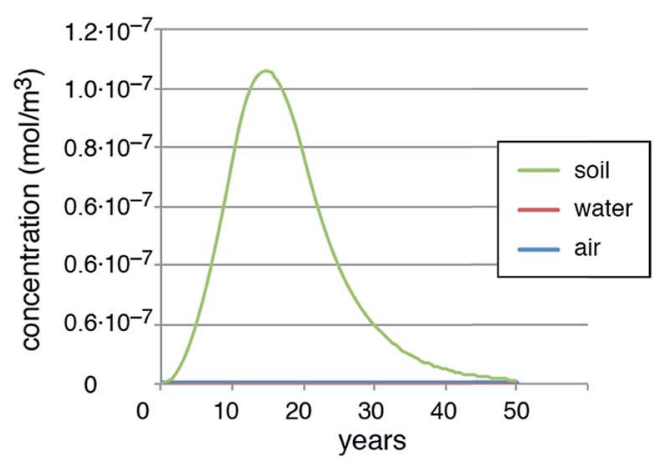

Fig. 2 Concentrations of chemicals C (panel (i)) and D (panel (ii)) as function of time in the scenario with dynamic emissions. For both chemicals, emissions start in year 0 , increase by $10 \mathrm{~mol} \mathrm{~h}^{-1}$ every year, peak in year 10 at a value of $100 \mathrm{~mol} \mathrm{~h}^{-1}$, then decrease by $10 \mathrm{~mol} \mathrm{~h}{ }^{-1}$ every year, and end in year 20. Note the much higher levels of chemical D compared to chemical C.

$1.19 \times 10^{5}$, which is much more than the 1000 -fold increase in the half-lives.

An increase in $\log K_{\text {OW }}$ by $6 \log$ units leads to a shift of the chemical from air and water to soil (see panels (i) and (ii) in Fig. 1). However, this does not change the overall persistence because in the examples presented here each chemical has the same degradation half-life in all environmental media. For short-lived chemicals the half-lives often vary markedly between environmental media, but in the case of highly persistent chemicals such as PFASs the half-lives are long in all media and degradation is slower than all phase-partitioning processes. Therefore, in the case of highly persistent chemicals, the partitioning properties $\left(\right.$ e.g. $\left.K_{\mathrm{OW}}\right)$ are not important for controlling the overall persistence of a chemical in the environment.

In the scenario with dynamic emissions, the concentrations of the short-lived chemical (chemical C) directly follow the time course of the emissions (Fig. 2, panel (i)). This illustrates that it is easily possible to quickly reduce even high concentrations of a short-lived chemical by reducing the emissions. The longlived chemical (chemical D), in contrast, shows a marked overshoot with increasing concentrations for more than 4 years after the emission peak in year 10 (concentration peak in year 14.5, see Fig. 2, panel (ii)). Moreover, the decreasing concentrations form a long tail that extends for many years after the stop of the emissions in year 20. This type of behavior is also visible in reality for PCBs and other highly persistent chemicals after the stop of major emissions, see overview and references in Table 1.

PFAAs are a class of chemicals with extremely long degradation half-lives in all media and it is therefore interesting to compare their environmental behavior with our modeling results. A steady-state condition was never reached for PFAAs because production continually increased between 1950 and 2000 until action to reduce emissions was taken. Even if emissions had levelled off at their production peak in the late 1990s, our modeling results imply that environmental levels would have continued to increase for many decades afterwards. Since action to reduce emissions of PFAAs commenced, starting in 2000-2002, there has been no evidence of consistent declines of any PFAA in the environment or biota. ${ }^{63}$ Perfluoroalkyl carboxylic acids with nine or more carbons continue to increase in human blood even after measures to reduce their emissions were introduced. ${ }^{63}$

\section{Discussion and recommendations}

\section{Model-derived findings}

The model results presented above illustrate the important general implications of high persistence: the higher the persistence of a chemical, the longer the time-to-steady state, the higher the steady-state concentrations, and the greater the overshoot and long-lasting contamination tail after the end of the emissions. Another important finding from the model results is that the $K_{\mathrm{OW}}$ does not modify these general implications of high persistence. The $K_{\mathrm{OW}}$ does modify the specific properties and environmental distribution of a chemical, but if the degradation half-lives are long in all media, the persistencerelated concerns (high time-to-steady state, overshoot, etc.) are present irrespective of the values of the partition coefficients. This has an important implication: a high $K_{\mathrm{OW}}$ is generally related to a high bioaccumulation factor, ${ }^{81}$ and a high bioaccumulation factor is an additional source of concern, but the fundamental concerns related to high persistence are independent of any bioaccumulation ("B") properties of a chemical. $B$ is not a useful criterion for protecting against poorly reversible effects because the residence time of highly persistent chemicals in the environment is often much greater than their residence time in humans and biota, which means that levels in organisms will be poorly reversible regardless of the magnitude of B. ${ }^{7}$ The irrelevance of environmental partitioning with regard to regulation of highly persistent chemicals is reflected on the regulatory side by two regulatory schemes that both focus on persistent chemicals, in one case with high $K_{\mathrm{OW}}$ (Stockholm Convention on POPs, $K_{\text {OW }}$ cutoff of $\log K_{\text {OW }}>5$ ), ${ }^{82}$ and in one case with low $K_{\mathrm{OW}}$ (the proposed scheme for persistent, mobile and toxic (PMT) chemicals with a cutoff of $\left.\log K_{\mathrm{OW}}<4\right) .{ }^{9,83,84}$ 


\section{Policy implications of the findings}

Based on the findings presented above, our general proposal is that, in addition to existing chemical assessment schemes, high persistence should be established as a sufficient basis for regulation of a chemical. We call this the "P-sufficient" approach (a similar reasoning supporting the P-sufficient approach has been presented by Goldenman et $a .^{10}{ }^{10}$. Current chemical assessment schemes place special emphasis on persistent chemicals only if other hazardous properties, such as bioaccumulation potential and toxicity, are also present, whereas high persistence as such is not relevant in chemicals assessment. For example, under REACH the identification of a substance as PBT or vPvB (very persistent and very bioaccumulative) automatically requires the registrant to carry out an estimate of emissions, to identify and implement measures to minimize emissions, to indicate in the safety data sheet (SDS) that the substance is $\mathrm{PBT} / \mathrm{vPvB}$, and to communicate measures for minimizing emissions to downstream users via the SDS. However, if a chemical is identified as $\mathrm{P}$ or $\mathrm{vP}$, but neither PBT nor $\mathrm{vPvB}$, there is no requirement to estimate and mitigate emissions nor any requirement to consider future continuing emissions in the risk assessment. This is a gap in the current European chemical assessment and management schemes, given that concentrations in the environment and, thereby, also PEC/PNEC ratios keep increasing for a long time for highly persistent chemicals if emissions continue. As far as we know, these deficiencies exist in all international chemical regulation schemes because high persistence in itself is not used as a trigger for regulation in any jurisdiction.

The P-sufficient approach, in contrast, means that high persistence is sufficient for a chemical to be flagged for subsequent management actions. For example, under REACH, the vP criteria could be used for this purpose. ${ }^{10}$ If a chemical exceeds the vP criteria, the P-sufficient approach would imply that this is sufficient to require estimation (and minimization) of emissions as occurs currently for PBT and $\mathrm{VPvB}$ chemicals. Furthermore, the implication of vP properties could be that the chemical is listed as a Substance of Very High Concern (SVHC) without any consideration of its other properties (i.e. $\mathrm{B}$ and $\mathrm{T}$ in the case of PBT, or $\mathrm{vB}$ in the case of $\mathrm{vPvB})$. Here the reference to the $\mathrm{VP}$ criteria under REACH is merely a suggestion for how the P-sufficient approach may be implemented. The actual cutoff value(s) for identifying highly persistent chemicals remain to be defined in a subsequent step.

When high persistence is identified for a chemical, the uses of this chemical should be grouped into essential and nonessential uses as a basis for determining management actions. ${ }^{85}$ Essential uses are uses that are indispensable for the health and/or safety of a certain population of workers, of patients under certain medical treatments, or of other groups, and for which there are no technically and economically feasible alternatives. Non-essential uses, on the other hand, are uses for which there are alternatives or where a substance has no essential technical function in a product and the use is driven only by convenience or market opportunity. These nonessential uses of a substance with high persistence could then be phased out with highest priority, whereas for essential uses measures should be taken that help avoid emissions (no widedispersive applications, collection and recycling, etc.). In the longer term, alternatives for these uses should also be developed.

\section{Empirical basis for the proposed "P sufficient" approach}

Technically, the P-sufficient approach could be based on the same type of evidence that is currently used for, e.g., the vP assessment under REACH. The substances currently classified as $\mathrm{vPvB}$ substances in the EU include, a.o., dechlorane plus, short-chain chlorinated paraffins, UV absorbers, long-chain perfluorocarboxylic acids, PFHxS, musk xylene, and the cyclic volatile methylsiloxanes D4, D5, and D6. A review of the SVHC dossiers of these substances shows that a range of different data has been used for the determination of vP properties. In several cases, simulation tests and field dissipation studies were available (UV absorbers, anthracene oils, short-chain chlorinated paraffins, some of the long-chain perfluorocarboxylic acids). These were often complemented by negative results from tests for ready or inherent biodegradability. In other cases (PFHxS, long-chain PFCAs, D6), read-across from similar chemicals with results from simulation tests for degradation was applied. In one case (deca-BDE), the formation of highly persistent transformation products was used as a reason why the substance was classified as vP. In the same way as for the current $\mathrm{VPvB}$ determinations, all these types of data can be used under the P-sufficient approach. If read-across is not possible, simulation tests or field dissipation studies may have to be performed, but this can be done under existing test guidelines. The formation of highly persistent transformation products will also be an important type of evidence, in particular for many PFASs that have reactive endgroups and will form - highly persistent - PFAAs in the environment.

On the one hand, it is advantageous that different types of data can be used for persistence determinations, as outlined above. On the other hand, there is a great need for one particular type of data, namely empirical degradation test results from a large, diverse set of chemicals with intermediate to high persistence. A broader empirical basis of degradation test results will help identify the types and number of highly persistent chemicals and will provide a basis for the development of improved methods for estimating degradation halflives from the chemical structure.

\section{The P-sufficient approach and the precautionary principle}

As pointed out in Section 2, the concern underlying any chemical hazard assessment is about adverse effects. In the context of persistence assessments, this is often expressed in such a way that $\mathrm{P}$ seemingly only matters in addition to $\mathrm{B}$ and $\mathrm{T}$. This is enshrined in the current PBT assessment schemes, see above, part 2 of this Discussion section, but was already clearly reflected, for example, in the following quote from an internal 3M document from the $1980 \mathrm{~s},{ }^{86}$

"Perhaps the most important conclusion from previous studies is the stability of fluorochemicals. Although stability is 
one of the most desirable properties fluorochemicals possess for many applications, from an environmental perspective, "stability" connotes "persistence" which can be the cause of concern especially when coupled with other properties. For example, some fluorochemicals have a tendency to accumulate in biological tissues. Moreover, some fluorochemicals have biological activity. This is most seriously demonstrated by the use of some fluorochemicals as pesticides. This is not to say that all fluorochemicals accumulate or that all have biological activity. But taken together, stability, the tendency to bioaccumulate, and biological activity are a potentially troublesome combination".

In contrast to this approach, the key point of the $\mathrm{P}$ sufficient approach is that this evidence of some type of effect should not be required to be demonstrated explicitly: because the possible effects cannot be predicted with sufficient reliability and remain incompletely known or entirely unknown, high persistence alone should be used as a sufficient indicator that serves as a proxy for adverse effects (see the reasoning provided in Section 2). Often, using a proxy of actual impacts as a basis for decision-making is considered an application of the precautionary principle. ${ }^{5,87,88}$ The precautionary principle states that, "where there are threats of serious or irreversible damage, lack of full scientific certainty shall not be used as a reason for postponing cost-effective measures to prevent environmental degradation". ${ }^{89}$

A problem with the implementation of the precautionary principle has been that the call for action based on limited evidence is often considered over-cautious. However, the empirical evidence that has accumulated over the last decades shows that it would not be over-cautious to restrict or regulate the use of highly persistent chemicals. When the known cases of highly persistent chemicals are considered, it shows that many of them have caused serious environmental impacts. Accordingly, there is a very high likelihood that additional highly persistent chemicals will also cause some kind of relevant environmental impact. Therefore, regulating highly persistent chemicals on the basis of their persistence alone may well be called an act of prevention, not just of precaution. In other words, it is entirely rational and empirically well founded to take high persistence seriously as a proxy of unwanted environmental impacts and to base preventive action on it.

There are also persistent chemicals that exert relatively low toxicity according to current knowledge, such as trifluoroacetic acid (TFA). ${ }^{90}$ The point of the P-sufficient approach is exactly that also highly persistent chemicals for which the currently known toxicity is rather low should be flagged and considered for regulation. As outlined above, it is well possible that unwanted effects occur at a large scale if such a chemical enters the environment, is distributed widely, and leads to continuously increasing environmental and human exposure. The evidence available from the last 50 years shows that this is not just a hypothetical possibility, but a highly likely outcome.

Similarly, the P-sufficient approach is also potentially suitable for synthetic polymers, which are (very) poorly degradable by their very nature. Jurisdictions around the world have various ways of defining when a substance is a synthetic polymer based on, for example, molecular weight, number of monomers, percentage impurities etc. We therefore do not provide a specific definition of a synthetic polymer here. Many high-molecularweight synthetic polymers have traditionally been treated as of low concern under chemical assessment and management schemes due to their low bioavailability. However, as elaborated above, once released, (unexpected) adverse effects by highly persistent chemicals may not only be biological effects, but also be physical or chemical effects. In the case of a subclass of highmolecular-weight synthetic polymers, namely plastics, an increasing number of wildlife mortality by entanglement or ingestion of marine plastic debris has been observed (e.g., Wilcox et al. (2015) ${ }^{91}$ ). In addition, plastics may break down into many smaller pieces (i.e., microplastics), which is another issue of emerging concern..$^{92,93}$ The P-sufficient approach is also in line with the recent call of classifying plastic waste as hazardous ${ }^{94}$ as well as it being flagged as a planetary boundary threat. ${ }^{95,96}$

\section{Conflicts of interest}

There are no conflicts of interest to declare.

\section{Acknowledgements}

We thank the Global PFAS Science Panel for travel support and helpful discussions.

\section{References}

1 M. E. Stephenson, An approach to the identification of organic compounds hazardous to the environment and human health, Ecotoxicol. Environ. Saf., 1977, 1, 39-48.

2 W. Klöpffer, Environmental Hazard- Assessment of chemicals and products, Environ. Sci. Pollut. Res., 1994, 1, 108.

3 E. Webster, D. Mackay and F. Wania, Evaluating environmental persistence, Environ. Toxicol. Chem., 1998, 17, 2148-2158.

4 D. Mackay, D. M. Hughes, M. L. Romano and M. Bonnell, The role of persistence in chemical evaluations, Integr. Environ. Assess. Manage., 2014, 10, 588-594.

5 EEA, Late Lessons from Early Warnings: The Precautionary Principle 1896-2000, European Environment Agency, Copenhagen, 2001.

6 L. M. Persson, M. Breitholtz, I. T. Cousins, C. A. de Wit, M. MacLeod and M. S. McLachlan, Confronting Unknown Planetary Boundary Threats from Chemical Pollution, Environ. Sci. Technol., 2013, 47, 12619-12622.

7 I. T. Cousins, R. Vestergren, Z. Wang, M. Scheringer and M. S. McLachlan, The precautionary principle and chemicals management: The example of perfluoroalkyl acids in groundwater, Environ. Int., 2016, 94, 331-340.

$8 \mathrm{M}$. Matthies and S. Beulke, Considerations of temperature in the context of the persistence classification in the $\mathrm{EU}$, Environ. Sci. Eur., 2017, 29, 15. 
9 H. P. H. Arp, T. N. Brown, U. Berger and S. E. Hale, Ranking $\mathrm{REACH}$ registered neutral, ionizable and ionic organic chemicals based on their aquatic persistency and mobility, Environ. Sci.: Processes Impacts, 2017, 19, 939-955.

10 G. Goldenman, R. Pedersen, H. Bradley, M. Fernandez, R. Weber, M. Scheringer and P. Fantke, Study for the strategy for a non-toxic environment of the 7th EAP. Sub-study d: Very Persistent Chemicals, Milieu, Ltd, Brussels, 2017.

11 R. Frische, G. Esser, W. Schönborn and W. Klöpffer, Criteria for assessing the environmental behavior of chemicals: Selection and preliminary quantification, Ecotoxicol. Environ. Saf., 1982, 6, 283-293.

12 M. Scheringer and M. Berg, Spatial and temporal range as measures of environmental threat, Fresenius Environ. Bull., 1994, 3, 493-498.

13 EEA, EEA, Late lessons from early warnings II: Science, precaution, innovation, European Environment Agency, 2013.

14 R. A. Hites, Elements of Environmental Chemistry, WileyBlackwell, Hoboken, N.J, 1st edn, 2007.

15 European Chemicals Agency, Guidance on Information Requirements and Chemical Safety Assessment, Chapter R.11: $\mathrm{PBT} / \mathrm{vPvB}$ Assessment, Version 3.0., European Chemicals Agency, Helsinki, Finland, 2017.

16 European Chemicals Bureau, Technical Guidance Document on Risk Assessment. Part II: Environmental Risk Assessment, European Commission Joint Research Centre, Ispra, Italy, 2003.

17 P. D. Jepson and R. J. Law, Persistent pollutants, persistent threats, Science, 2016, 352, 1388-1389.

18 H. Duan, T. R. Miller, G. Liu, X. Zeng, K. Yu, Q. Huang, J. Zuo, Y. Qin and J. Li, Chilling Prospect: Climate Change Effects of Mismanaged Refrigerants in China, Environ. Sci. Technol., 2018, 52, 6350-6356.

19 S. A. Montzka, G. S. Dutton, P. Yu, E. Ray, R. W. Portmann, J. S. Daniel, L. Kuijpers, B. D. Hall, D. Mondeel, C. Siso, J. D. Nance, M. Rigby, A. J. Manning, L. Hu, F. Moore, B. R. Miller and J. W. Elkins, An unexpected and persistent increase in global emissions of ozone-depleting CFC-11, Nature, 2018, 557, 413-417.

20 Z. Wang, J. C. DeWitt, C. P. Higgins and I. T. Cousins, A Never-Ending Story of Per- and Polyfluoroalkyl Substances (PFASs)?, Environ. Sci. Technol., 2017, 51, 2508-2518.

21 F. S. Rowland, Stratospheric Ozone Depletion by Chlorofluorocarbons (Nobel Lecture), Angew. Chem., Int. Ed. Engl., 1996, 35, 1786-1798.

22 J. Borja, D. M. Taleon, J. Auresenia and S. Gallardo, Polychlorinated biphenyls and their biodegradation, Process Biochem., 2005, 40, 1999-2013.

23 M. D. Hurley, M. P. Sulbaek Andersen, T. J. Wallington, D. A. Ellis, J. W. Martin and S. A. Mabury, Atmospheric Chemistry of Perfluorinated Carboxylic Acids: Reaction with $\mathrm{OH}$ Radicals and Atmospheric Lifetimes, J. Phys. Chem. A, 2004, 108, 615-620.

24 J. S.-C. Liou, B. Szostek, C. M. DeRito and E. L. Madsen, Investigating the biodegradability of perfluorooctanoic acid, Chemosphere, 2010, 80, 176-183.
25 S. Vaalgamaa, A. V. Vähätalo, N. Perkola and S. Huhtala, Photochemical reactivity of perfluorooctanoic acid (PFOA) in conditions representing surface water, Sci. Total Environ., 2011, 409, 3043-3048.

26 D. Liu, Z. Xiu, F. Liu, G. Wu, D. Adamson, C. Newell, P. Vikesland, A.-L. Tsai and P. J. Alvarez, Perfluorooctanoic acid degradation in the presence of $\mathrm{Fe}(\mathrm{III})$ under natural sunlight, J. Hazard. Mater., 2013, 262, 456-463.

27 M. McFarland and J. Kaye, Chlorofluorocarbons and Ozone, Photochem. Photobiol., 1992, 55, 911-929.

28 P. De voogt and U. A. T. Brinkman, in Halogenated Biphenyls, Terphenyls, Naphthalenes, Dibenzodioxins and Related Products, ed. R. D. Kimbrough and A. A. Jensen, Elsevier, Amsterdam, 2nd edn, 1989, pp. 3-45.

29 Fluorinated Surfactants and Repellents, ed. E. Kissa, CRC Press, New York, 2nd edn, 2001.

$30 \mathrm{~J}$. E. Lovelock, A sensitive detector for gas chromatography, J. Chromatogr. A, 1958, 1, 35-46.

$31 \mathrm{~J}$. E. Lovelock, Atmospheric Fluorine Compounds as Indicators of Air Movements, Nature, 1971, 230, 379.

32 J. E. Lovelock, R. J. Maggs and R. J. Wade, Halogenated Hydrocarbons in and over the Atlantic, Nature, 1973, 241, 194-196.

33 S. Jensen, Report of a new chemical hazard, New Sci., 1966, 32, 612 .

34 S. Jensen, A. G. Johnels, M. Olsson and G. Otterlind, DDT and PCB in Marine Animals from Swedish Waters, Nature, 1969, 224, 247-250.

35 D. R. Taves, Evidence that there are Two Forms of Fluoride in Human Serum, Nature, 1968, 217, 1050-1051.

36 W. S. Guy, D. R. Taves and W. S. Brey, in Biochemistry Involving Carbon-Fluorine Bonds, American Chemical Society, 1976, vol. 28, pp. 117-134.

37 M. J. Molina and F. S. Rowland, Stratospheric sink for chlorofluoromethanes: chlorine atom-catalysed destruction of ozone, Nature, 1974, 249, 810-812.

$38 \mathrm{~J}$. P. Giesy and K. Kannan, Global distribution of perfluorooctane sulfonate in wildlife, Environ. Sci. Technol., 2001, 35, 1339-1342.

39 K. J. Hansen, L. A. Clemen, M. E. Ellefson and H. O. Johnson, Compound-Specific, Quantitative Characterization of Organic Fluorochemicals in Biological Matrices, Environ. Sci. Technol., 2001, 35, 766-770.

40 F. Wania and D. MacKay, Peer Reviewed: Tracking the Distribution of Persistent Organic Pollutants, Environ. Sci. Technol., 1996, 30, 390A-396A.

41 R. W. Risebrough, W. Walker II, T. T. Schmidt, B. W. De Lappe and C. W. Connors, Transfer of chlorinated biphenyls to Antarctica, Nature, 1976, 264, 738-739.

42 S. Dasgupta, X. Peng, S. Chen, J. Li, M. Du, Y.-H. Zhou, G. Zhong, H. Xu and K. Ta, Toxic anthropogenic pollutants reach the deepest ocean on Earth, Geochem. Perspect. Lett., 2018, 7, 22-26.

43 D. C. Muir, R. Wagemann, B. T. Hargrave, D. J. Thomas, D. B. Peakall and R. J. Norstrom, Arctic marine ecosystem contamination, Sci. Total Environ., 1992, 122, 75-134. 
44 N. Yamashita, K. Kannan, S. Taniyasu, Y. Horii, G. Petrick and T. Gamo, A global survey of perfluorinated acids in oceans, Mar. Pollut. Bull., 2005, 51, 658-668.

45 K. Rankin, S. A. Mabury, T. M. Jenkins and J. W. Washington, A North American and global survey of perfluoroalkyl substances in surface soils: Distribution patterns and mode of occurrence, Chemosphere, 2016, 161, 333-341.

46 M. Houde, J. W. Martin, R. J. Letcher, K. R. Solomon and D. C. G. Muir, Biological monitoring of polyfluoroalkyl substances: A review, Environ. Sci. Technol., 2006, 40, 34633473.

47 R. Vestergren and I. T. Cousins, Tracking the pathways of human exposure to perfluorocarboxylates, Environ. Sci. Technol., 2009, 43, 5565-5575.

48 P. Casal, Y. Zhang, J. W. Martin, M. Pizarro, B. Jiménez and J. Dachs, Role of Snow Deposition of Perfluoroalkylated Substances at Coastal Livingston Island (Maritime Antarctica), Environ. Sci. Technol., 2017, 51, 8460-8470.

49 C. Eschauzier, E. Beerendonk, P. Scholte-Veenendaal and P. De Voogt, Impact of treatment processes on the removal of perfluoroalkyl acids from the drinking water production chain, Environ. Sci. Technol., 2012, 46, 1708-1715.

50 D. A. Fisher, C. H. Hales, W.-C. Wang, M. K. W. Ko and N. D. Sze, Model calculations of the relative effects of CFCs and their replacements on global warming, Nature, 1990, 344, 513-516.

51 S. Jensen, B. Jansson and M. Olsson, Number and identity of anthropogenic substances known to be present in Baltic seals and their possible effects on reproduction, Ann. N. Y. Acad. Sci., 1979, 320, 436-448.

52 J. Koivusaari, I. Nuuja, R. Palokangas and M. Finnlund, Relationships between productivity, eggshell thickness and pollutant contents of addled eggs in the population of white-tailed eagles Haliaeetus albicilla L. in Finland during 1969-1978, Environ. Pollut., Ser. A, 1980, 23, 41-52.

53 G. G. Fein, J. L. Jacobson, S. W. Jacobson, P. M. Schwartz and J. K. Dowler, Prenatal exposure to polychlorinated biphenyls: effects on birth size and gestational age, J. Pediatr., 1984, 105, 315-320.

54 W. J. Rogan, B. C. Gladen, J. D. McKinney, N. Carreras, P. Hardy, J. Thullen, J. Tinglestad and M. Tully, Neonatal effects of transplacental exposure to PCBs and DDE, $J$. Pediatr., 1986, 109, 335-341.

55 B. C. Gladen, W. J. Rogan, P. Hardy, J. Thullen, J. Tingelstad and M. Tully, Development after exposure to polychlorinated biphenyls and dichlorodiphenyl dichloroethene transplacentally and through human milk, J. Pediatr., 1988, 113, 991-995.

56 J. C. DeWitt, Toxicological Effects of Perfluoroalkyl and Polyfluoroalkyl Substances, Humana Press, 2015.

57 P. Grandjean, Delayed discovery, dissemination, and decisions on intervention in environmental health: a case study on immunotoxicity of perfluorinated alkylate substances, Environ. Health, 2018, 17, 62.

58 M. P. Chipperfield, S. S. Dhomse, W. Feng, R. L. McKenzie, G. J. M. Velders and J. A. Pyle, Quantifying the ozone and ultraviolet benefits already achieved by the Montreal Protocol, Nat. Commun., 2015, 6, 7233.

59 C. Bogdal, N. Niggeler, J. Glüge, P. S. Diefenbacher, D. Wächter and K. Hungerbühler, Temporal trends of chlorinated paraffins and polychlorinated biphenyls in Swiss soils, Environ. Pollut., 2017, 220, 891-899.

60 M. Desmet, B. Mourier, B. J. Mahler, P. C. Van Metre, G. Roux, H. Persat, I. Lefèvre, A. Peretti, E. Chapron, A. Simonneau, C. Miège and M. Babut, Spatial and temporal trends in PCBs in sediment along the lower Rhône River, France, Sci. Total Environ., 2012, 433, 189-197.

61 S. P. Bhavsar, D. A. Jackson, A. Hayton, E. J. Reiner, T. Chen and J. Bodnar, Are PCB Levels in Fish from the Canadian Great Lakes Still Declining?, J. Great Lakes Res., 2007, 33, 592-605.

62 Z. Wang, I. T. Cousins, M. Scheringer, R. C. Buck and K. Hungerbühler, Global emission inventories for C4-C14 perfluoroalkyl carboxylic acid (PFCA) homologues from 1951 to 2030, Part I: production and emissions from quantifiable sources, Environ. Int., 2014, 70, 62-75.

63 M. Land, C. A. de Wit, A. Bignert, I. T. Cousins, D. Herzke, J. H. Johansson and J. W. Martin, What is the effect of phasing out long-chain per- and polyfluoroalkyl substances on the concentrations of perfluoroalkyl acids and their precursors in the environment? A systematic review, Environ. Evid., 2018, 7, 4.

64 H. I. Gomes, C. Dias-Ferreira and A. B. Ribeiro, Overview of in situ and ex situ remediation technologies for PCBcontaminated soils and sediments and obstacles for fullscale application, Sci. Total Environ., 2013, 445-446, 237260.

65 N. Merino, Y. Qu, R. A. Deeb, E. L. Hawley, M. R. Hoffmann and S. Mahendra, Degradation and Removal Methods for Perfluoroalkyl and Polyfluoroalkyl Substances in Water, Environ. Eng. Sci., 2016, 33, 615-649.

66 U.S. Air Force Civil Engineer Center, U.S. Air Force Civil Engineer Center > What We Do > Environment > Perfluorinated-Compounds > FAQs > Investivation/ Mitigation Cost, https://www.afcec.af.mil/What-We-Do/ Environment/Perfluorinated-Compounds/FAQs/ \#Investigation/Mitigation-Cost, accessed 4 November 2018.

67 J. L. Pirkle, W. H. Wolfe, D. G. Patterson, L. L. Needham, J. E. Michalek, J. C. Miner, M. R. Peterson and D. L. Phillips, Estimates of the half-life of 2,3,7,8tetrachlorodibenzo- $p$-dioxin in Vietnam veterans of operation ranch hand, J. Toxicol. Environ. Health, 1989, 27, 165-171.

68 K. M. Yeager, P. H. Santschi, H. S. Rifai, M. P. Suarez, R. Brinkmeyer, C.-C. Hung, K. J. Schindler, M. J. Andres and E. A. Weaver, Dioxin Chronology and Fluxes in Sediments of the Houston Ship Channel, Texas: Influences of Non-Steady-State Sediment Transport and Total Organic Carbon, Environ. Sci. Technol., 2007, 41, 5291-5298.

69 J. M. Armitage, M. S. McLachlan, K. Wiberg and P. Jonsson, A model assessment of polychlorinated dibenzo- $p$-dioxin and 
dibenzofuran sources and fate in the Baltic Sea, Sci. Total Environ., 2009, 407, 3784-3792.

70 P. Schmid, M. Kohler, A. C. Gerecke, E. Gujer, M. Zennegg and M. Wolfensberger, Old Sins Throw Long Shadows; Old and Emerging Persistent Organic Pollutants in the Swiss Environment, Chimia, 2003, 57, 509-513.

71 R. J. Law, A. Covaci, S. Harrad, D. Herzke, M. A.-E. Abdallah, K. Fernie, L.-M. L. Toms and H. Takigami, Levels and trends of PBDEs and HBCDs in the global environment: status at the end of 2012, Environ. Int., 2014, 65, 147-158.

72 M. Venier, A. Salamova and R. A. Hites, Halogenated Flame Retardants in the Great Lakes Environment, Acc. Chem. Res., 2015, 48, 1853-1861.

73 L. Camenzuli, M. Scheringer and K. Hungerbühler, Local organochlorine pesticide concentrations in soil put into a global perspective, Environ. Pollut., 2016, 217, 11-18.

74 D. Fagin, Toxicology: The learning curve, Nature, 2012, 490, 462.

75 B. A. Woodcock, J. M. Bullock, R. F. Shore, M. S. Heard, M. G. Pereira, J. Redhead, L. Ridding, H. Dean, D. Sleep, P. Henrys, J. Peyton, S. Hulmes, L. Hulmes, M. Sárospataki, C. Saure, M. Edwards, E. Genersch, S. Knäbe and R. F. Pywell, Country-specific effects of neonicotinoid pesticides on honey bees and wild bees, Science, 2017, 356, 1393-1395.

76 D. Mackay, Finding fugacity feasible, Environ. Sci. Technol., 1979, 13, 1218-1223.

77 D. Mackay, Multimedia Environmental Models: The Fugacity Approach, 2nd edn, CRC Press, 2001.

78 J. Armitage, I. T. Cousins, R. C. Buck, K. Prevedouros, M. H. Russell, M. MacLeod and S. H. Korzeniowski, Modeling global-scale fate and transport of perfluorooctanoate emitted from direct sources, Environ. Sci. Technol., 2006, 40, 6969-6975.

79 J. R. Parsons, M. Sáez, J. Dolfing and P. de Voogt, Biodegradation of perfluorinated compounds, Rev. Environ. Contam. Toxicol., 2008, 196, 53-71.

80 J. M. Boucher, I. T. Cousins, M. Scheringer, K. Hungerbühler and Z. Wang, Toward a Comprehensive Global Emission Inventory of C4-C10 Perfluoroalkanesulfonic Acids (PFSAs) and Related Precursors: Focus on the Life Cycle of C6- and C10-Based Products, Environ. Sci. Technol. Lett., 2019, 6, 1-7.

81 F. A. Gobas, W. de Wolf, L. P. Burkhard, E. Verbruggen and K. Plotzke, Revisiting Bioaccumulation Criteria for POPs and PBT Assessments, Integr. Environ. Assess. Manage., 2009, 5, 624-637.

82 UNEP, Stockholm Convention on Persistent Organic Pollutants, http://www.pops.int/TheConvention/Overview/ TextoftheConvention/tabid/2232/Default.aspx, accessed 4 November 2018.

83 German Environment Agency, Protecting the sources of our drinking water, German Environment Agency, 06813 Dessau-Roßlau, 2017.

84 T. Reemtsma, U. Berger, H. P. H. Arp, H. Gallard, T. P. Knepper, M. Neumann, J. B. Quintana and P. de Voogt, Mind the Gap: Persistent and Mobile Organic
Compounds-Water Contaminants That Slip Through, Environ. Sci. Technol., 2016, 50, 10308-10315.

85 A. Ritscher, Z. Wang, M. Scheringer, J. M. Boucher, L. Ahrens, U. Berger, S. Bintein, S. K. Bopp, D. Borg, A. M. Buser, I. Cousins, J. DeWitt, T. Fletcher, C. Green, D. Herzke, C. Higgins, J. Huang, H. Hung, T. Knepper, C. S. Lau, E. Leinala, A. B. Lindstrom, J. Liu, M. Miller, K. Ohno, N. Perkola, Y. Shi, L. Småstuen Haug, X. Trier, S. Valsecchi, K. van der Jagt and L. Vierke, Zürich Statement on Future Actions on Per- and Polyfluoroalkyl Substances (PFASs), Environ. Health Perspect., 2018, 126, 84502.

86 3M Internal Correspondence, Letter to Olson CW. Subject: Fluorochemicals in the Environment, 1992.

87 M. Berg and M. Scheringer, Problems in environmental risk assessment and the need for proxy measures, Fresenius Environ. Bull., 1994, 3, 487-492.

88 EEA, Chemicals in the European environment: low doses, high stakes?, European Environment Agency, Copenhagen, 1998.

$89 \mathrm{UN}$, Report of the United Nations conference on environment and development, Annex I: Rio Declaration on environment and development, United Nations, 1992.

90 K. R. Solomon, G. J. M. Velders, S. R. Wilson, S. Madronich, J. Longstreth, P. J. Aucamp and J. F. Bornman, Sources, fates, toxicity, and risks of trifluoroacetic acid and its salts: Relevance to substances regulated under the Montreal and Kyoto Protocols, J. Toxicol. Environ. Health, Part B, 2016, 19, 289-304.

91 C. Wilcox, E. V. Sebille and B. D. Hardesty, Threat of plastic pollution to seabirds is global, pervasive, and increasing, Proc. Natl. Acad. Sci. U. S. A., 2015, 112, 11899-11904.

92 GESAMP, Sources, Fate and Effects of Microplastics in the Marine Environment (Part 2), IMO/FAO/UNESCO-IOC/ UNIDO/WMO/IAEA/UN/UNEP/UNDP Joint Group of Experts on the Scientific Aspects of Marine Environmental Protection, 2016.

93 GESAMP, Sources, fate and effects of microplastics in the marine environment (Part 1), GESAMP, IMO/FAO/UNESCOIOC/UNIDO/WMO/IAEA/UN/UNEP/UNDP Joint Group of Experts on the Scientific Aspects of Marine Environmental Protection, 2015.

94 C. M. Rochman, M. A. Browne, B. S. Halpern, B. T. Hentschel, E. Hoh, H. K. Karapanagioti, L. M. RiosMendoza, H. Takada, S. Teh and R. C. Thompson, Policy: Classify plastic waste as hazardous, Nature, 2013, 494, 169171.

95 P. Villarrubia-Gómez, S. E. Cornell and J. Fabres, Marine plastic pollution as a planetary boundary threat - The drifting piece in the sustainability puzzle, Mar. Pol., 2018, 96, 213-220.

96 A. Jahnke, H. P. H. Arp, B. I. Escher, B. Gewert, E. Gorokhova, D. Kühnel, M. Ogonowski, A. Potthoff, C. Rummel, M. Schmitt-Jansen, E. Toorman and M. MacLeod, Reducing Uncertainty and Confronting Ignorance about the Possible Impacts of Weathering Plastic in the Marine Environment, Environ. Sci. Technol. Lett., 2017, 4, 85-90. 